\title{
Large Skull Defect in a Headbanger
}

\author{
Karen J. Stuck and R. J. Hernandez \\ Department of Radiology, University of Michigan Medical Center, Ann Arbor, Michigan, USA
}

\begin{abstract}
A mentally retarded self-mutilating child developed a large skull defect at the site of repeated trauma. The bony defect involved only the outer table and had smooth bony margins.
\end{abstract}

Key words: Headbanger - Skull defect - Skull Trauma

\section{Case Report}

\section{Clinical History}

S. T. is a 10 year old white boy, first seen on $1 / 21 / 77$ for mental retardation. He was described as having had delayed developmental milestones, first walking at age 2 and rarely speaking. At age 3 he began self-destructive behavior, described by his family as exhibiting headbanging, biting and hitting. He was diagnosed in 1977 as having mental retardation and infantile autism. His IQ was less than 30. Though he had some features of Lesch-Nyhan disease, all the neurological abnormalities of this syndrome were not present and biochemical evaluation was normal.

He was seen again on $7 / 28 / 78$ for evaluation of soft tissue swelling and a bony defect in the right frontal bone of the skull. The lesion was in the area that had been repeatedly traumatized by the patient banging his right knee against his forehead.

It was felt that the lesion was secondary to trauma and the patient was fitted with a protective helmet. There was no local or systemic evidence for an infectious process involving the frontal bone.

Follow-up evaluation of $10 / 20 / 78$ showed a decrease in the soft tissue swelling, with no other significant change in the character of the lesion. The family has been advised to have S. T. continue to wear the protective helmet.

\section{Roentgenographic Examinations}

The initial skull series obtained on 1/24/77 was normal except for mild microcephaly. The examination of $7 / 28 / 78$ showed a saucer shaped bony defect in the right frontal bone measuring $4 \mathrm{~cm}$ in

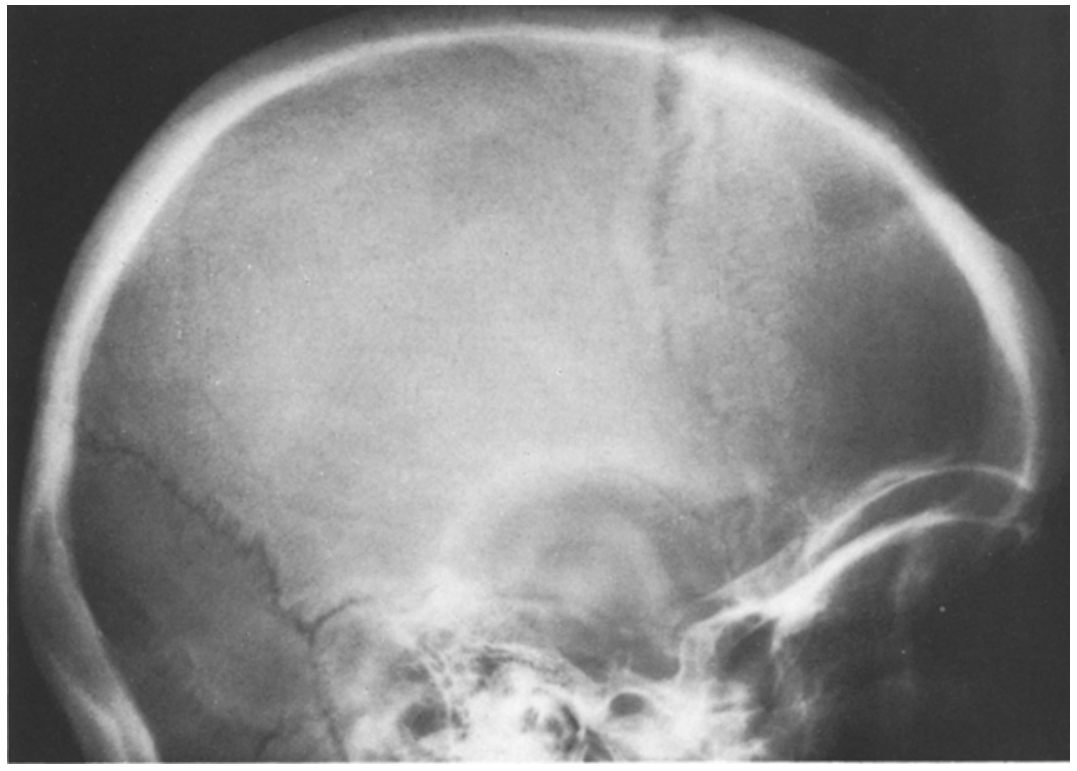

Fig. 1. Lateral view of the skull on $7 / 28 / 78$ showing the bony defect in the right frontal bone 
diameter which corresponded exactly to the point of contact of the right knee and forehead. The defect involved only the outer table and was smoothly marginated. There was soft tissue swelling overlying the defect. There was no associated change in bone mineralization. Follow-up radiographs on 10/20/78 showed no significant change other than a decrease in the overlying soft tissue swelling.

\section{Discussion}

Roentgenographic changes in headbangers have been described to include thickening of the calvaria secondary to repeated subperiosteal hemorrhage, diastasis of the cranial sutures, soft tissue hematomas, calcification in the eye, cauliflower ears and hematoma of the corpus callosum [3]. A solitary bony lesion at the site of repeated trauma has not been described.

Erosion of the outer table of the calvaria is indicative of a mass in the scalp of long duration, the most common mass being a sebaceous cyst [2]. This patient's skull series obtained on $1 / 21 / 77$ showed no bony changes and no suggestion of a scalp lesion. It is unlikely a cyst could subsequently have developed to cause such extensive bony erosion in only 18 months. Other possible lesions to the scalp include metastases and infections. The bony mineralization is abnormal and patchy, in these lesions, with areas of bony destruction and thinning adjacent to areas of reparative sclerosis and thickening $[1,2]$. In this case, the radiographic appearance was not typical of osteomyelitis. The bony mineralization was normal and only the outer table was involved. The static nature of the defect is atypical for osteomyelitis.
Other solitary lesions which might be included in the differential diagnosis include histiocytosis X, epidermoid and hemangioma. The lesion of histiocytosis most commonly involves the full thickness of the calvarium and has beveled edges [1, 2]. Epidermoids grow in the diploe and erode bony trabeculae by pressure. The margins are well corticated by new compact bone being produced at the periphery of the lesion [2]. A hemangioma also frequently begins in the diploe and bony spiculation can be seen within the lesion. This case is not typical for any of these lesions.

This case illustrates the effect of repeated trauma to one area of the skull, causing a local erosive outer table defect without any evidence for associated bony infection.

\section{References}

1. Harwood-Nash, D. C., Fitz, C. R.: Neuroradiology in infants and children. St. Louis: C. V. Mosby Co. 1976

2. Newton, T. H., Potts, D. G.: Radiology of the skull and brain. St. Louis: C. V. Mosby Co. 1971

3. Williams, J. P., Fowler, G. W., Pribram, H. F., Delaney, C. A., Fish, C. H.: Roentgenographic changes in headbangers. Acta Radiol. [Diagn.] (Stockh.) 13, 37 (1972)

Date of final acceptance: December 20, 1978

R. J. Hernandez, M. D.

Division of Pediatric Radiology

C. S. Mott Children's Hospital

University of Michigan Medical Center

Ann Arbor, MI 48109

USA 